\title{
A MORE ACCURATE METHOD OF MEASUREMENT OF ANGULATION AFTER FRACTURES OF THE TIBIA
}

\author{
S. A. MILNER
}

From the University Hospital, Nottingham, England

Accurate measurement of the alignment of the tibia is important both clinically and in research. The conventional method of measuring the angle of malunion after a fracture of the shaft of the tibia is potentially inaccurate because the mechanical axis of the normal bone may not pass down the centre of the medullary canal.

An alternative method is described in which a radiograph of the opposite tibia is used as a template. A sample of 56 sets of standard radiographs of healed fractures of the shaft of the tibia was evaluated. The 95\% limits of agreement between this and the conventional method were wide, being $-6.2^{\circ}$ to $+5.5^{\circ}$ for coronal angulation and $-6.7^{\circ}$ to $+8.1^{\circ}$ for sagittal angulation.

These results suggest that the conventional method is inaccurate. The new method has good inter- and intraobserver reliability.

J Bone Joint Surg [Br] 1997;79-B:972-4.

Received 29 November 1996; Accepted after revision 24 June 1997

It is uncertain whether malalignment of the tibia after malunion of a fracture of the shaft causes osteoarthritis of the knees and ankles. ${ }^{1-4}$ Further investigation requires accurate measurement of any angulation of the fracture. It is usual to measure the angle between lines drawn distally from the centre of the knee down the middle of the proximal shaft, and proximally from the centre of the ankle up the middle of the distal shaft (Fig. 1). The slight ' $S$ '

S. A. Milner, FRCS, Research Fellow in Orthopaedic Surgery University Department of Orthopaedic Surgery, University Hospital, Queens Medical Centre, Nottingham NG7 2UH, UK.

Correspondence should be sent to Mr S. A. Milner at the Department of Orthopaedic Surgery, Derbyshire Royal Infirmary, London Road, Derby DE1 2QY, UK.

(C)1997 British Editorial Society of Bone and Joint Surgery 0301-620X/97/67458\$2.00 shape of the shaft of the tibia in many normal individuals means that the mechanical axis of the normal bone rarely passes down the middle of the medullary canal (Fig. 2); this makes the conventional method of measuring the angulation of malunion potentially unreliable. A new method which avoids this problem is presented.

\section{METHODS}

In the normal subject, the right and left tibiae form a mirror image of each other. In patients with malunion of a unilateral fracture, a standard radiograph of the contralateral tibia can be used as a template to show the proximal and distal segments of the original mechanical axis. This is marked on the radiograph of the normal side as a straight line between the centre of the knee and the centre of the ankle, defined as the midpoint of the distal tibial articular surface (Fig. 2). This radiograph is turned over and the radiograph of the fracture is laid over it. By superimposing successively the proximal and distal parts of the tibia, the corresponding proximal and distal segments of the original mechanical axis of the tibia can be accurately traced on to the radiograph of the fracture. When the radiographs are very dense, a piece of acetate film can be used as an intermediate template. The method is illustrated in Figure 3 , using the same radiograph as in Figure 1. The intersection of the two lines is at the centre of rotation of angulation (CORA), ${ }^{5}$ and the angle between them is the true degree of malunion in that plane.

The CORA may not coincide with the centre of the fracture, and minimal angulation with considerable translation may cause the CORA to lie outside the field of the radiograph. In such cases, the mechanical axis after the fracture, from the centre of the knee to the centre of the ankle, can be marked on the radiograph. The angles between this line and the two related segments of the normal mechanical axis are measured. The angle of malunion is then the difference between these two angles.

The new method was evaluated in 56 sets of standard radiographs of healed fractures of the shaft of the tibia which had been treated by immobilisation in plaster. A 


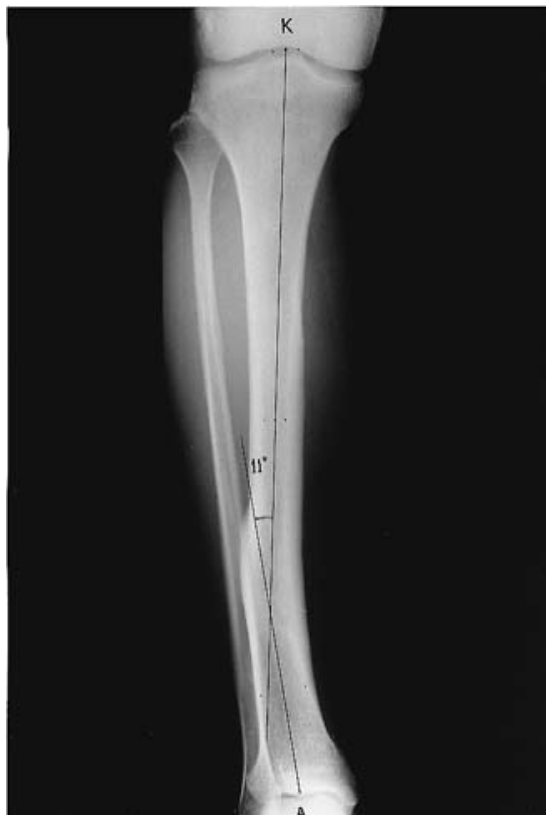

Fig. 1

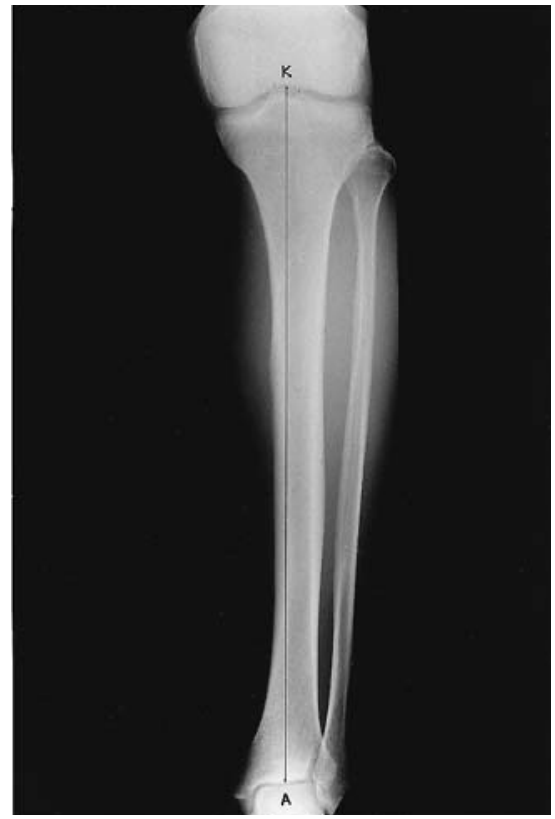

Fig. 2

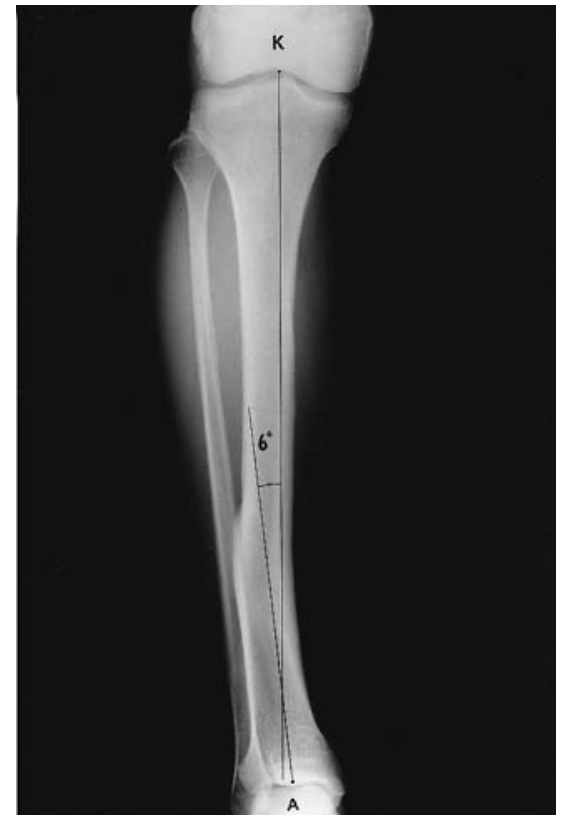

Fig. 3

Figure 1 - Radiograph showing the conventional method of measurement in malunion of $11^{\circ}$ varus. Figure 2 - Radiograph showing the mechanical axis on the contralateral tibia. Figure $3-$ The same radiograph as in Figure 1 showing the new method of measurement giving malunion of $6^{\circ}$ varus.

random sample of 20 of the sets of radiographs was remeasured by the same observer, blinded to the first result, and by a second observer who had received only written instruction in the method. Angles were measured to the nearest $0.5^{\circ}$, using a protractor.

\section{RESULTS}

The difference between the angles obtained using the old and new methods ranged from $-10^{\circ}$ to $+6.5^{\circ}$ for anteroposterior films and $-11.5^{\circ}$ to $+7.5^{\circ}$ for lateral films. The $95 \%$ limits of agreement between the methods were $-6.2^{\circ}$ to $+5.5^{\circ}$ for coronal angulation and $-6.7^{\circ}$ to $+8.1^{\circ}$ for sagittal angulation.

The mean intraobserver difference was $-0.2^{\circ}$ (95\% limits of agreement $-2.5^{\circ}$ to $+2.2^{\circ}$ ) for anteroposterior films and $-0.1^{\circ}\left(95 \%\right.$ limits of agreement $-3.3^{\circ}$ to $\left.+3.3^{\circ}\right)$ for lateral films. The mean interobserver difference was $-0.1^{\circ}(95 \%$ limits of agreement $-2.9^{\circ}$ to $+2.6^{\circ}$ ) for anteroposterior films and $-0.3^{\circ}\left(95 \%\right.$ limits of agreement $-3.1^{\circ}$ to $\left.+2.4^{\circ}\right)$ for lateral films.

\section{DISCUSSION}

Variability in clinical measurements can arise from intersubject variation, errors in measurement and observer error. A clinical measurement is useful only when errors of measurement and observer error are small compared with intersubject variation. Measurement error includes variiation introduced by radiographic technique and also by the method used to measure the malunion angle on the radio- graph. The error which may arise from variation in radiographic technique has been investigated in an experimental model by Floyd $^{6}$ who showed that in the absence of malrotation, angles could be measured to within $1^{\circ}$ of the true angle. All the radiographs in this study were taken with the patella pointing forwards, using a standard X-ray exposure and tube distance. Because radiographic error is likely to be minimal, it was not felt necessary to validate the method against a 'dry-bones' model of malunion of a fracture. It has been shown that the conventional method of measurement of the angle of malunion is subject to error in a considerable number of patients, sometimes in excess of $10^{\circ}$. The intra- and interobserver variation has been shown to be small when compared with errors due to the conventional method.

There are other advantages. The bony landmarks used to define the mechanical axis of the tibia are not critical, because they are very similar on each side. The method can be used for metaphyseal fractures, but the accuracy was less with very proximal and very distal injuries. It also has potential for use on other long bones.

The main limitations are that it can be used only when the two sides form an accurate mirror image. This is impossible if there is significant rotational malunion of the fracture, malunion of a fracture on the opposite side, or when there are bony changes associated with severe osteoarthritis. In most patients, however, the method is a clinically useful means of measuring the angle of malunion on anteroposterior and lateral views of a fracture of the shaft of the tibia. Calculation of the total angulation from these views has been described. ${ }^{7}$ 
The author is funded by the Arthritis \& Rheumatism Council for Research. He wishes to thank Mr T. R. C. Davis for remeasurement of the radiographs and $\mathrm{Mr} \mathrm{D}$. Greenwood for valuable statistical advice.

No benefits in any form have been received or will be received from a commercial party related directly or indirectly to the subject of this article.

\section{REFERENCES}

1. Kristensen KD, Kiaer T, Blicher J. No arthrosis of the ankle 20 years after malaligned tibial-shaft fracture. Acta Orthop Scand 1989;60 208-9.

2. Merchant TC, Dietz FR. Long-term follow-up after fractures of the tibial and fibular shafts. J Bone Joint Surg [Am] 1989;71-A:599606.
3. Puno RM, Vaughan JJ, Stetten ML, Johnson JR. Long-term effects of tibial angular malunion on the knee and ankle joints. J Orthop Trauma 1991;5:247-54.

4. Van Der Schoot DKE, Den Outer AJ, Bode PJ, Obermann WR, van Vugt $\mathbf{A B}$. Degenerative changes at the knee and ankle related to malunion of tibial fractures: 15 -year follow-up of 88 patients. $J$ Bone Joint Surg [Br] 1996;78-B:722-5.

5. Paley D, Tetsworth K. Mechanical axis deviation of the lower limbs: preoperative planning of multiapical frontal plane angular and bowing deformities of the femur and tibia. Clin Orth 1992;280:65-71.

6. Floyd AS. Is the measurement of angles on radiographs accurate? A brief report. J Bone Joint Surg [Br] 1988;70-B:486-7.

7. Bridgman SA, Baird K. Audit of closed tibial fractures: what is a satisfactory outcome? Injury 1993;24:85-9. 